Supporting information for

\title{
Dynamic Covalent Polymer Networks based on Degenerative Imine Bond Exchange: Tuning the Malleability and Self-Healing Properties by Solvent
}

\author{
Albert Chao, $\dagger$ Ioan Negulescut and Donghui Zhang ${ }^{*} \dagger$ \\ Department of Chemistry and Macromolecular Studies Group, Louisiana State University, \\ Baton Rouge, LA 70803
}

Corresponds to: Donghui Zhang (dhzhang@1su.edu)

\section{Experimental}

General considerations. All chemicals used in the study were purchased from Sigma-Aldrich except for the PEG diamine $\left(M_{\mathrm{n}}=1,000 \mathrm{~g} \cdot \mathrm{mol}^{-1}\right)$ which was purchased from Laysan Bio Inc. Model imine compounds (i.e., $(E)$-N-benzylidenepropan-1-amine and $(E)$ N-benzylideneprop-2-en-1-amine) were prepared by literature procedures ${ }^{1}$ and distilled and stored under nitrogen before being used in the kinetic studies. The control sample is a thiolacrylate thermoset derived from trimethylolpropane tris(3-mercaptopropianate) and trimethylolpropane triacrylate in the presence of a catalytic amount of tertiary amine by a literature procedure. ${ }^{2}$ Aluminum molding plate (each mold is $\mathrm{d}=10 \mathrm{~mm}, \mathrm{~h}=3 \mathrm{~mm}$ ) was made from LSU mechanical shop. Deuterated acetonitrile and toluene were dried with calcium hydride and freeze pump thaw $(3 x)$ followed by vacuum transfer. Deuterated DMF was dried with sodium hydride for $1 \mathrm{~h}$ in the glove box and filtered before use.

Preparation of monomer and organogels. 1,3,5-Triformylbenzene (trialdehyde, Scheme S1) was synthesized following a published procedure. ${ }^{3}$ Cross-linked polymeric gels were prepared by dissolving the PEO diamine $\left(M_{\mathrm{n}}=1,000,1,500,3,000 \mathrm{~g} \cdot \mathrm{mol}^{-1}\right)$ in various solvents with slight heating and then allowing the solution to cool down to room temperature before addition of the trialdehyde. A representative procedure is given as followed. PEO diamine ( $\left.100 \mathrm{mg}, 0.067 \mathrm{mmol}, M_{\mathrm{n}}=1,500 \mathrm{~g} \cdot \mathrm{mol}^{-1}\right)$ was dissolved in DMF $(370 \mu \mathrm{L})$ follow by adding trialdehyde $(7.2 \mathrm{mg}, 0.044 \mathrm{mmol})$ to make [amine $]_{0}=[\text { aldehyde }]_{0}=0.37 \mathrm{M}$ solution. After the solution became homogeneous, it was transferred to an aluminium mold slowly using a pipette to minimize air bubble formation. The mold was covered with two microscope slides at the top and bottom. The mixtures were allowed to stand in the mold at 
room temperature for $4 \mathrm{~h}$. Dyed organogels were prepared under the same conditions except that a DMF solution containing $5 \mathrm{wt} \%$ fluorescein or rhodamine B was used as the solvent. Neat polymer network samples were also made in a similar manner except that the monomers were mixed in an aluminium mold that was preheated at $50{ }^{\circ} \mathrm{C}$.

\section{Scheme S1.}

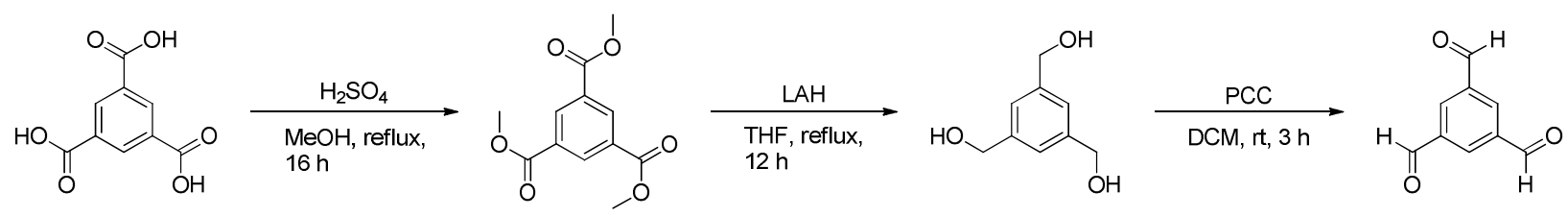

IR spectroscopy measurement. Imine conversion was measured by monitoring the disappearance of the aldehyde over time using ATR-FTIR spectrometer (Bruker Alpha). FTIR spectrum of the trialdehyde solution $(0.12 \mathrm{M})$ without PEO diamine was measured as reference. After $4 \mathrm{~h}$, FTIR spectrum of the organogel was measured again. The imine conversion was determined by the ratio of unreacted aldehyde to the initial aldehyde peak intensity.

Rheological measurements. In situ sol-to-gel transitions for the condensation polymerization was monitored using a TA instrument AR 1000 Rheometer with a parallelplate geometry $\left(50 \mathrm{~mm}\right.$ diameter and a fixed $300 \mu \mathrm{m}$ gap) at $1 \mathrm{~Hz}$ frequency at $20^{\circ} \mathrm{C}$. From oscillatory shear measurements the storage modulus G', the loss modulus G' and delta degree can be determined. The condensation polymerization mixture $(1 \mathrm{~mL})$ was loaded into the rheometer and covered with a round plastic lid to minimize solvent evaporation. Each experiment was stopped until delta degree reach to $40^{\circ}$.

Dynamic mechanical analysis (DMA). Strain relaxation (creep) and stress relaxation experiments were performed using TA instruments DMA Q800 under uniaxial compression mode. A couple drops of tetradecane were added onto the compressive parallel plates to reduce friction and adhesion between the plate and the gel disc. Strain relaxation measurements of the polymer gels were conducted at a constant stress $0.01 \mathrm{MPa}$ with a preload force $0.001 \mathrm{~N}$ for $5 \mathrm{~min}$ followed by load-free strain recovery for $5 \mathrm{~min}$. Stress relaxation experiments were conducted with a $10 \%$ strain in compression mode with a preload force $0.001 \mathrm{~N}$ for $5 \mathrm{~min}$. Deformation of the gels is described in term of percentage 
strain recovery that was calculated by $\left(\sigma_{\text {initial }}-\sigma_{\text {final }}\right) / \sigma_{\text {initial }}$. A triplicate of each polymeric gel was subjected to the same measurement for both strain and stress relaxation tests to get the mean result.

Kinetics studies of imine bond exchange. ${ }^{1} \mathrm{H}$ NMR spectra were recorded on a Bruker AV-400 spectrometer, and the chemical shifts in parts per million (ppm) were referenced relative to $A N-d_{3}, D M F-d_{7}$, or TOL- $d_{8}$. 1,3,5-Trimethoxybenzene was used as internal standard for the kinetic study. A representative procedure for the kinetic study is given as followed. Inside the glovebox, $(E)$ - $N$-benzylidenepropan-1-amine (10 $\mathrm{mg}, 0.07 \mathrm{mmol}),(E)$ $N$-(4-methoxybenzylidene)prop-2-en-1-amine $\quad(12 \mathrm{mg}, \quad 0.07 \quad \mathrm{mmol})$ and 1,3,5trimethoxybenzene $(11.4 \mathrm{mg}, 0.07 \mathrm{mmol})$ was dissolved in deuterated acetonitrile $\left(\mathrm{AN}-\mathrm{d}_{3}\right.$, $0.49 \mathrm{~mL}$ ) in a dried vial. The mixture was then transferred into a J. Young NMR tube followed by the addition of the $\mathrm{AN}-\mathrm{d}_{3}$ stock solution of $\mathrm{PrNH}_{2}(10 \mu \mathrm{L}, 6.8 \mathrm{mM}, 0.001$ eqv. relative to the total imine content) at room temperature. ${ }^{1} \mathrm{H}$ NMR spectra were collected immediately after the preparation of the reaction mixture. Each spectrum was collected with 8 scan and $2 \mathrm{~s}$ relaxation time at room temperature. All kinetic experiments were repeated twice to get the mean reaction rate.

Differential scanning calorimetry (DSC). DSC analysis of the neat polymer network was conducted using a TA DSC 2920 instrument. The polymer $(8.2 \mathrm{mg})$ was hermetically sealed in standard aluminium pan. An empty pan was used as reference. The sample was kept at $10{ }^{\circ} \mathrm{C}$ for $2 \mathrm{~min}$ and then heated to $65{ }^{\circ} \mathrm{C}$ at $5{ }^{\circ} \mathrm{C} \cdot \mathrm{min}^{-1}$. It was held at $65^{\circ} \mathrm{C}$ for another 2 min before being cooled back down to $10{ }^{\circ} \mathrm{C}$ at the same rate. The heating and cooling cycles were repeated 3 times. Heat flow was recorded during the heating and cooling cycles, and normalized by the sample mass.

Characterization of self-healing properties. Gel disc samples were cut with a razor blade and the half discs were re-attached at the cut-interface using a tweezer for $0.5,20$ and $48 \mathrm{~h}$ respectively at room temperature. These samples were then subjected to compressive strain-stress measurement using TA instruments DMA Q800 with the compressive force increasing in the $3 \mathrm{~N}-18 \mathrm{~N}$ range. A triplicate of the healed gel sample, the intact gel sample and the control sample were measured.

Adhesion study. A microscope glass slide was modified with amino functional groups by submerging one end of the glass slide in a toluene solution of (3-Aminopropyl)- 
triethoxysilane $(0.1 \%, \mathrm{v} / \mathrm{v})$ at room temperature for $5 \mathrm{~h}$ followed by rinsing with toluene and drying in air. Two IL gels (Entry 10, Table 1) were individually placed for one minute on each end of a glass slide that has been either functionalized with primary amine group or unmodified and then were scraped with a spatula to reveal whether adhesive or cohesive damage would occur.
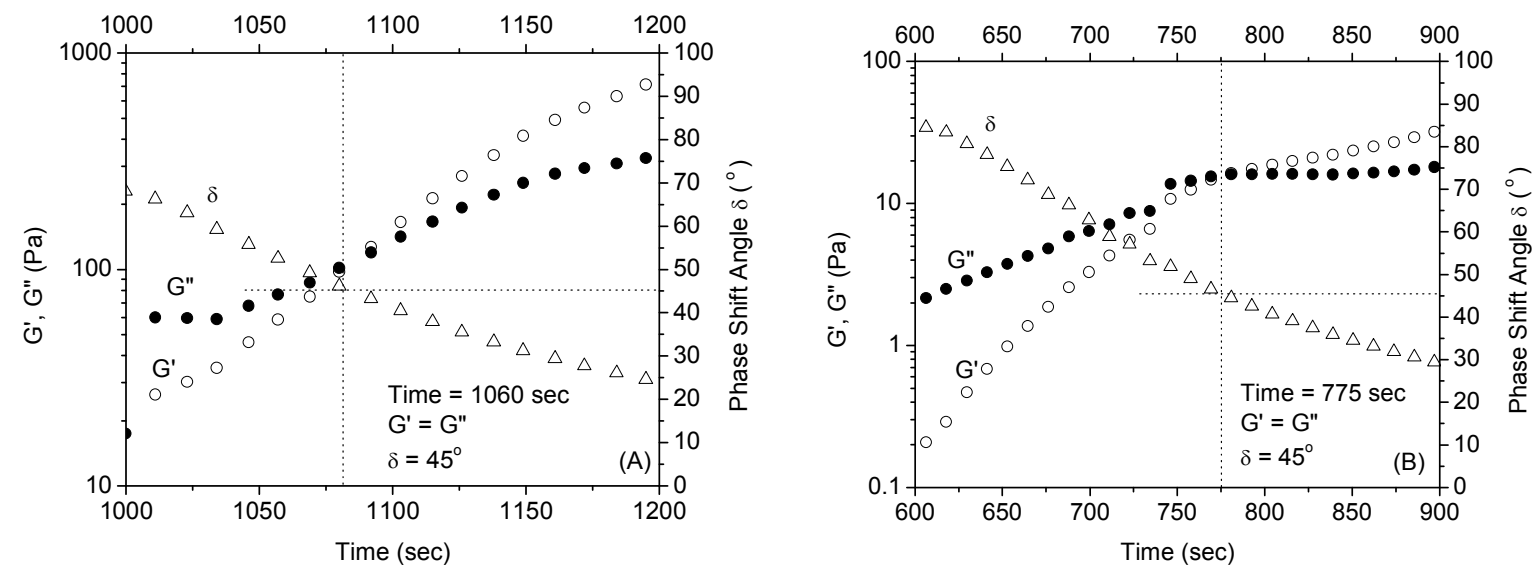

Figure S1. Plots of storage moduli $\left(\mathrm{G}^{\prime}, \bullet\right)$, loss moduli $\left(\mathrm{G}^{\prime},, \circ\right)$, and delta degree $(\Delta)$ versus time for the condensation polymerization mixtures of PEO diamines with varying molecular weight $\left[M_{\mathrm{n}}=\right.$ $1000(\mathrm{~A})$ and $\left.1500 \mathrm{~g} \cdot \mathrm{mol}^{-1}(\mathrm{~B})\right]$ and 1,3,5-triformylbenzene in a 1:1 molar ratio of the total amine to aldehyde functional groups in DMF at room temperature obtained by oscillatory rheological measurement at room temperature under a constant frequency $(\omega=1 \mathrm{~Hz})$. The initial concentrations of amine and aldehyde functional groups are both kept at $0.37 \mathrm{M}$. 

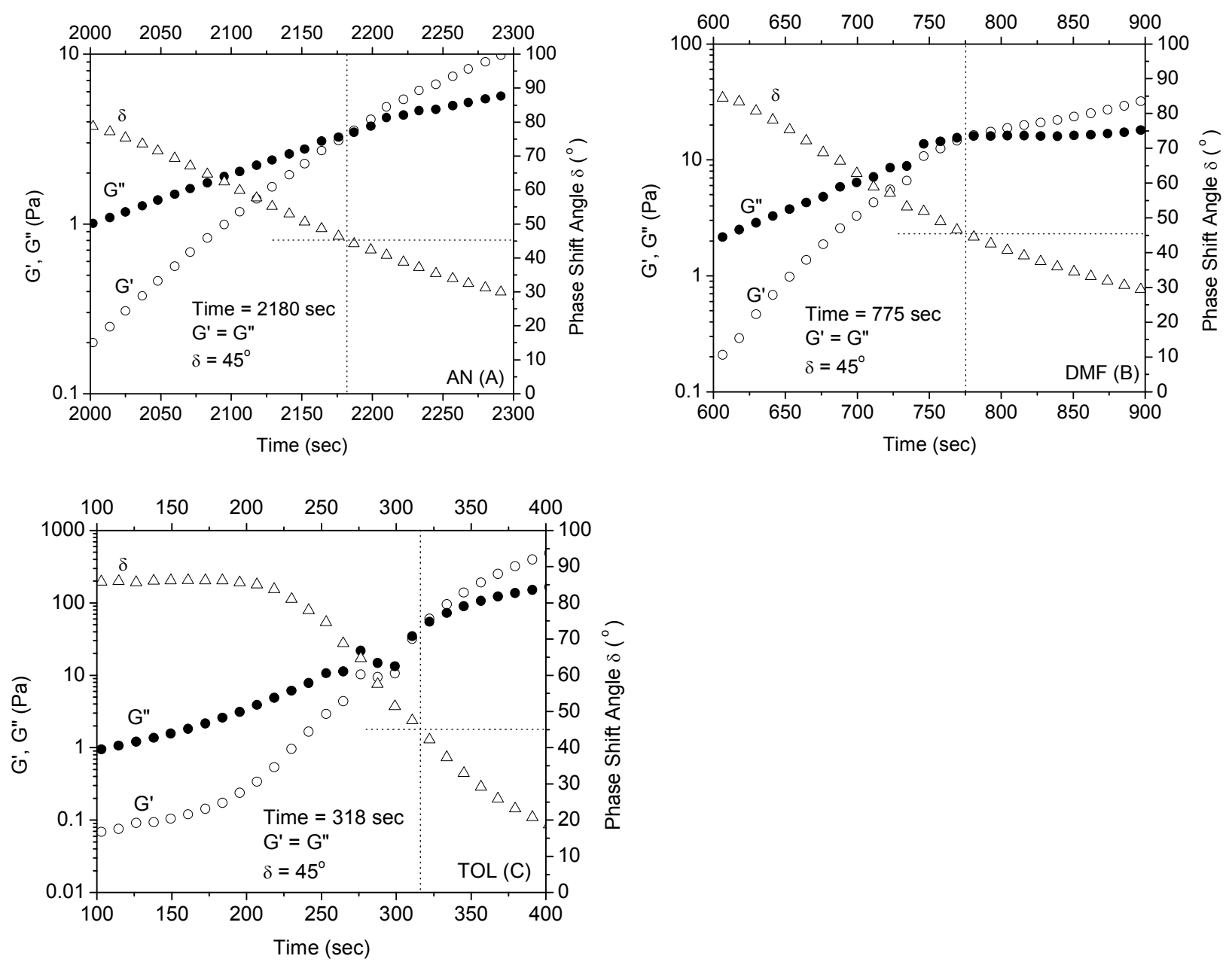

Figure S2. Plots of storage moduli $\left(\mathrm{G}^{\prime}, \bullet\right)$, loss moduli $\left(\mathrm{G}^{\prime},, \mathrm{O}\right)$, and delta degree $(\Delta)$ versus time for the condensation polymerization mixtures of PEO diamine $\left(M_{\mathrm{n}}=1500 \mathrm{~g} \cdot \mathrm{mol}^{-1}\right)$ and $1,3,5$ triformylbenzene in a 1:1 molar ratio of the total amine to aldehyde functional groups in various solvents [i.e., AN (A), DMF (B) and TOL (C)] at room temperature obtained by oscillatory rheological measurement at room temperature under a constant frequency $(\omega=1 \mathrm{~Hz})$. The initial concentrations of the amine and aldehyde functional groups are both kept at $0.37 \mathrm{M}$. 


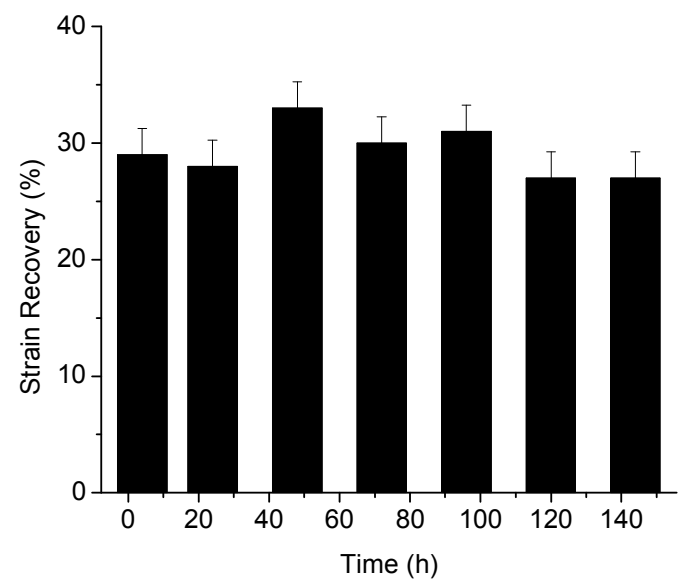

Figure S3. The plot of percentage strain recovery versus aging time for the dynamic covalent polymeric network comprised of low molecular weight PEG strands $\left(M_{\mathrm{n}}=1500 \mathrm{~g} \cdot \mathrm{mol}^{-1}\right)$ and imine cross-linkers in DMF (Entry 4, Table 1). The experiments were conducted in compression mode with a constant stress $(\sigma=0.01 \mathrm{MPa})$. The mean percentage recovery is $29 \pm 2 \%$.

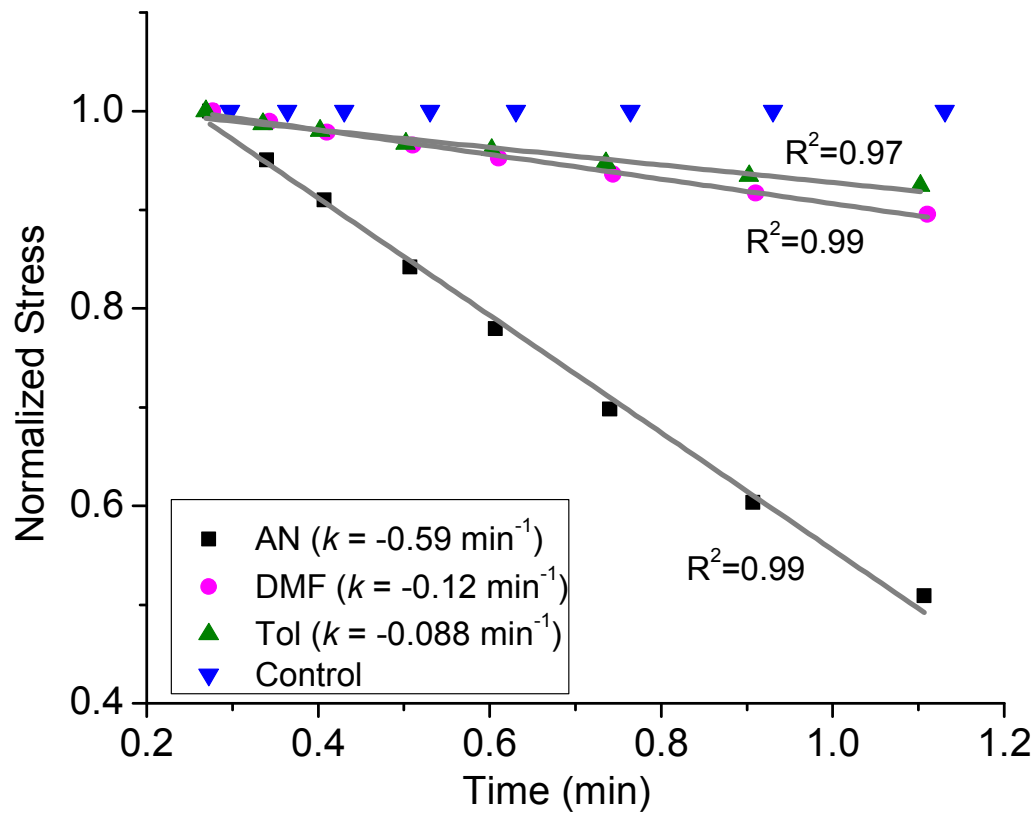

Figure S4. The plot of normalized stress versus time for the dynamic covalent polymeric network comprised of low molecular weight PEG strands $\left(M_{\mathrm{n}}=1500 \mathrm{~g} \cdot \mathrm{mol}^{-1}\right)$ and imine cross-linkers in various solvents (An, DMF and TOL) (Entry 3-5, Table 1) in the initial stage where the stress decays linearly with the time. The data was linearly fitted and the slope corresponds to the relative rate of the stress relaxation ( $k$ shown in the inset). 

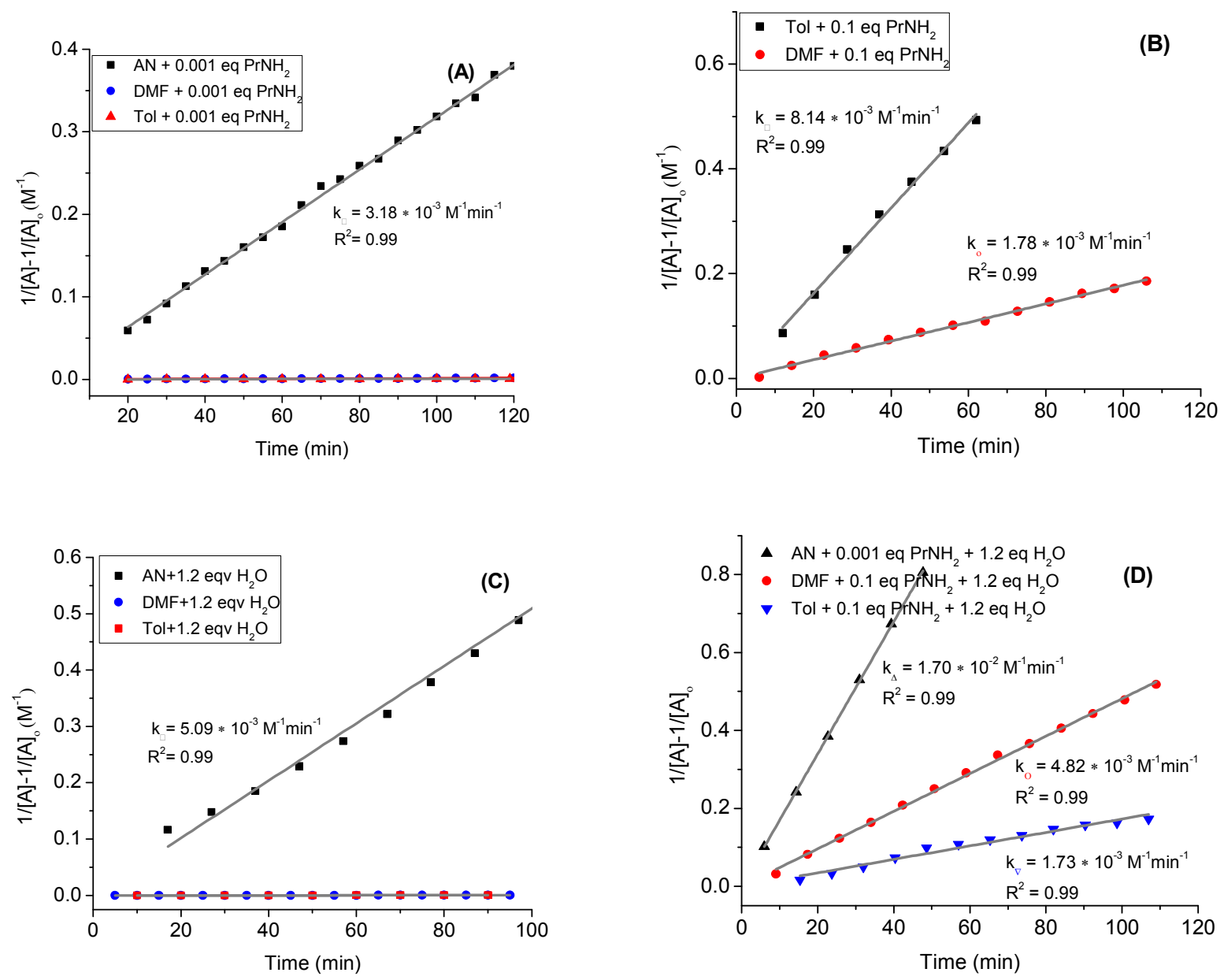

Figure S5. Kinetic studies of imine-imine exchange reactions using model imine compounds (Scheme 2) in the presence of a catalytic amount of $\mathrm{PrNH}_{2}, \mathrm{H}_{2} \mathrm{O}$ or a combination of both in various deuterated solvents $\left(A N-d_{3}, D M F-d_{7}\right.$ and TOL- $\left.d_{8}\right)$. 

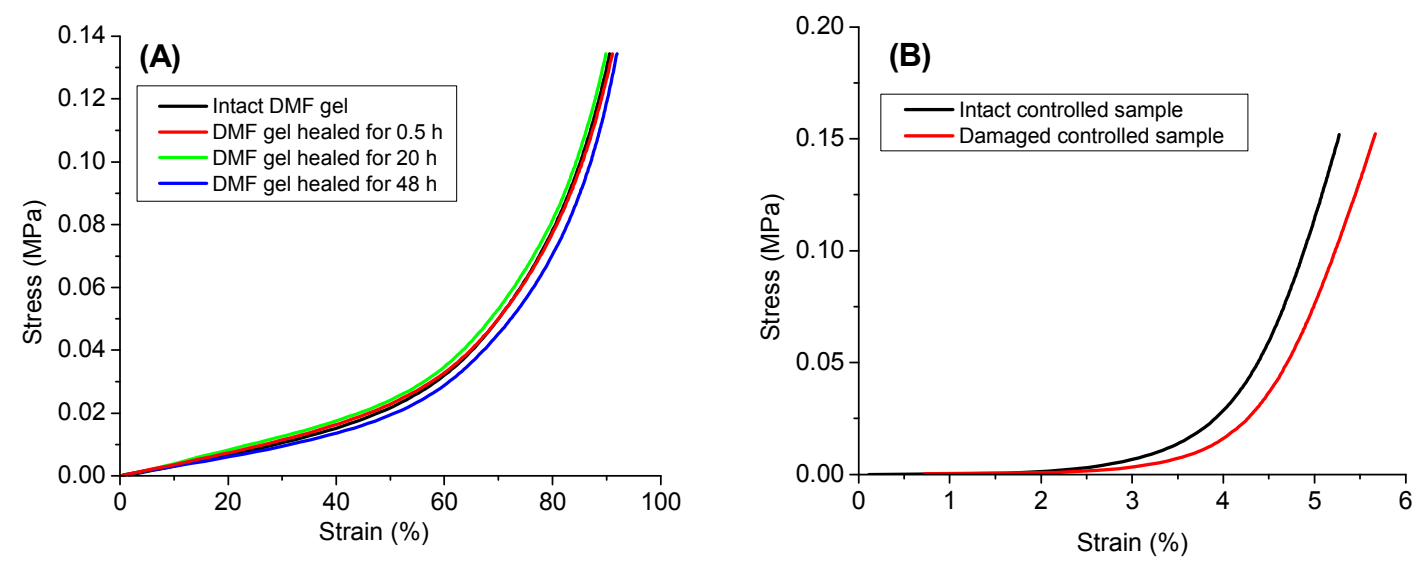

Figure S6. (A) The plot of compressive stress versus strain for the intact DMF gel (Entry 4, Table 1) and the DMF gels that were cut and allowed to heal for different duration $(0.5,24$ and $48 \mathrm{~h})$ by putting the two cut pieces together at the interface with a tweezer. (B) The plot of compressive stress versus strain for the intact control sample which is a polymeric thermoset and the damaged controlled sample after being cut and put together at the cut interface with a tweezer.

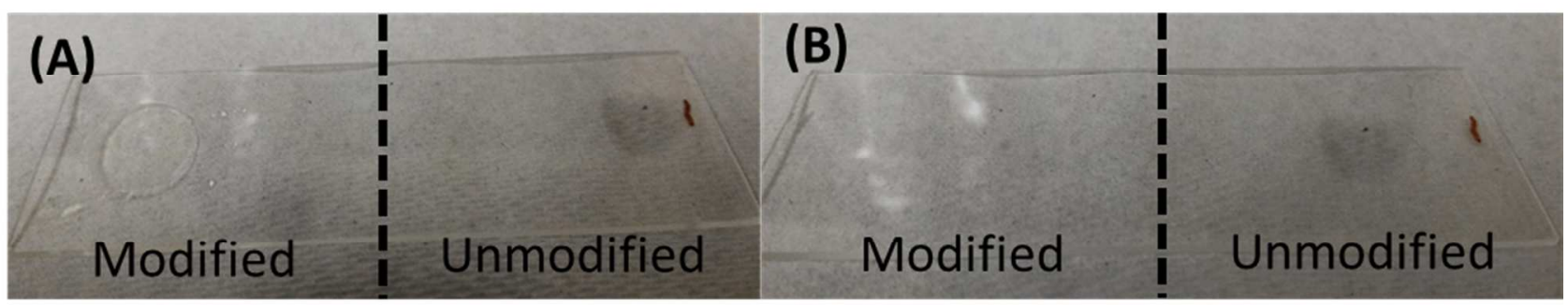

Figure S7. Optical images showing that the cohesively fractured IL gel that remains on the glass slide (Entry 10, Table 1) can be readily removed by first soaking in water for $10 \mathrm{~min}$ (A) and then wiping with a Kimwipe tissue paper (B). 


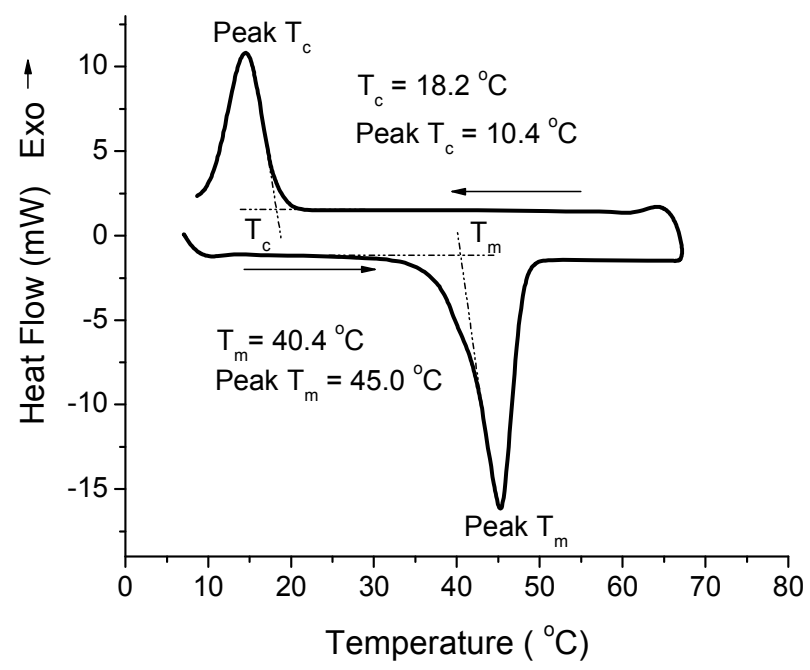

Figure S8. DSC analysis of the neat polymeric network comprised of low molecular weight PEG strands $\left(M_{\mathrm{n}}=1500 \mathrm{~g} \cdot \mathrm{mol}^{-1}\right)$ and imine cross-linkers (Entry 11, Table 1) showing a broad melting point $\left(\mathrm{T}_{\mathrm{m}}\right)$ at $\sim 40^{\circ} \mathrm{C}$.

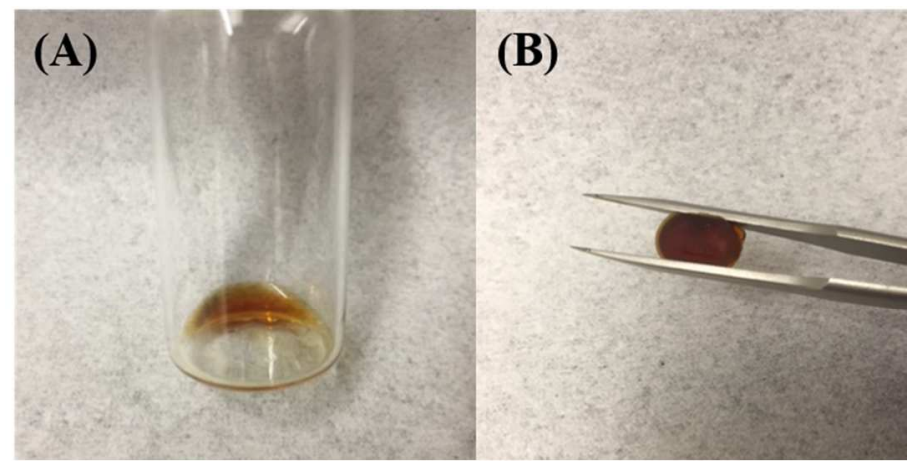

Figure S9. Optical images showing the low molecular PEO diamine $\left(M_{\mathrm{n}}=1500 \mathrm{~g} \cdot \mathrm{mol}^{-1}\right)$ itself and the neat polymeric network comprised of the low molecular weight PEG strands $\left(M_{\mathrm{n}}=1500 \mathrm{~g} \cdot \mathrm{mol}^{-1}\right)$ and imine cross-linkers at $50{ }^{\circ} \mathrm{C}$. The former became a free-flowing liquid as expected for a thermoplastic and the latter became rubbery due to the dynamic covalent crosslinking.

\section{Reference}

1. Hayes, J. F.; Hayler, J. D.; Walsgrove, T. C.; Wicks, C., Synthesis of new azepino[3,4,5cd]indole derivatives. Journal of Heterocyclic Chemistry 1996, 33 (1), 209-212.

2. Garber, L.; Chen, C.; Kilchrist, K. V.; Bounds, C.; Pojman, J. A.; Hayes, D., Thiol-acrylate nanocomposite foams for critical size bone defect repair: A novel biomaterial. Journal of Biomedical Materials Research Part A 2013, 101 (12), 3531-3541.

3. Pandey, P.; Katsoulidis, A. P.; Eryazici, I.; Wu, Y.; Kanatzidis, M. G.; Nguyen, S. T., ImineLinked Microporous Polymer Organic Frameworks. Chemistry of Materials 2010, 22 (17), 49744979. 